\title{
Capillary flow responses in a soil-plant system for modified subsurface precision irrigation
}

\author{
Mohamad Shukri Bin Zainal Abidin • Sakae Shibusawa • \\ Motoyoshi Ohaba • Qichen Li • Marzuki Bin Khalid
}

Published online: 2 April 2013

(C) The Author(s) 2013. This article is published with open access at Springerlink.com

\begin{abstract}
Water movement in a soil-plant system was evaluated based on capillary flow in a modified subsurface irrigation system that incorporates a plant-water measuring device. Water from a reservoir tank located underneath the plant pot was supplied to the root zone through a fibrous medium. Evapotranspiration was measured from the water uptake and evaluations were performed based on soil moisture distribution and mass balance. Potential evapotranspiration was used as a reference for the plant-water uptake. Data were obtained from a test plant provided with the modified subsurface irrigation system. The plant was grown in a phytotron under controlled air temperature and humidity, and a comparison was made for different levels of soil moisture condition. The experimental results confirmed the operational efficiency of the modified subsurface irrigation system for precision irrigation.
\end{abstract}

Keywords Water saving - Fibrous sheet - Subsurface irrigation · Capillary irrigation · Crop water demand $\cdot$ Soil-plant-atmosphere continuum

M. S. Bin Zainal Abidin ( ()

United Graduate School of Agricultural Science, Tokyo University of Agriculture and Technology, 3-5-8 Saiwai-cho, Fuchu 183-8509, Japan

e-mail: shukri75@yahoo.com

S. Shibusawa $\cdot$ M. Ohaba

Division of Environmental and Agricultural Engineering, Institute of Agriculture, Tokyo University of Agriculture and Technology, 3-5-8 Saiwai-cho, Fuchu 183-8509, Japan

Q. Li

Graduate School of Agriculture, Tokyo University of Agriculture and Technology, 3-5-8 Saiwai-cho, Fuchu 183-8509, Japan

M. Bin Khalid

Center for Artificial Intelligent and Robotic, University of Technology Malaysia, Jalan Semarak, Kuala Lumpur 54100, Malaysia 


\section{Introduction}

Recent droughts and severe floods around the world have led to increased concerns about water shortages not only for agriculture but also for industry and daily life. The $11 \mathrm{March}$, 2011 Great East Japan Earthquake, with the ensuing tsunami and nuclear plant disaster, caused shortages of fresh water for both human consumption and agricultural use. Watersaving management is a key technology not only for arid and drought-prone areas but also for disaster areas. This was the motivation to develop a site-specific irrigation system to meet the water demand for plant growth by applying precise control.

Various methods have been developed to supply small amounts of water to the root zone of plants. Subsurface drip irrigation has been proven to generate a higher yield and quality of crops grown in either open fields or greenhouse farms (Camp 1998). Subsurface irrigation relies on the concept of irrigating only the root zone of a crop while maintaining the soil moisture content at the optimum level (James 1988). Higher water-use efficiency can easily be achieved by manipulating the irrigation frequency and emitter arrangement (Camp 1998). Subsurface drip irrigation management is based on the soil moisture deficit determined by using a soil-water balance model or the crop-water requirement estimated using the energy balance method (Ayars et al. 1999; Jones 2004; Bonachela et al. 2006). A new measurement paradigm in irrigation management uses a crop-based method that enables the system to adapt to the variability in crop-water demand according to the individual crop-water response (Jones 2004; Raine et al. 2005; Smith and Baillie 2009). Progress has also been made by applying leaf temperature and sap flow measurement methods (Giorio and Giorio 2003; Jones and Leinonen 2003).

However, these methods for sensing plant water-stress involve complex measuring systems and provide minimum information on irrigation volume and timing; thus they can only be used on an experimental scale (Jones 2004). Nevertheless, further advancement of irrigation management strategy along this new paradigm is required. This project was developed based on the phytotechnology platform (Shibusawa 1989) for a site-specific irrigation system to meet the plant-water demand by applying precise control.

A recent trial using capillary flow from a water interface medium into the soil resulted in higher quality and water-use efficiency of greenhouse peppers (Nalliah and Ranjan 2010). The outcome led to a new irrigation strategy and was very beneficial to this study. Advancement of this method will allow precise measurement of individual crop-water characteristics and new strategies for efficient management of irrigation supply. However, crop-water demand and evapotranspiration from the trial results have not been determined in detail.

The present investigation attempts to enhance and analyze the crop-based method by using a simple modified subsurface irrigation system that enables continuous water supply and a sensing system for the plant-water requirement. The results were evaluated based on soil moisture distribution and mass balance approach to confirm the significance of the proposed system.

\section{Materials and methods}

\section{Theoretical approach}

The schematic used to describe the water movement of modified subsurface irrigation in a soil-plant system is shown in Fig. 1. In a soil-plant system, the water movement mainly 
depends on the water potential gradient (Slatyer 1967). The driving force of transpiration is the vapor pressure gradient between the leaf surface and the atmosphere. Water lost from a plant via transpiration is replenished by extracting water from the soil. Water moves through the soil into the roots, xylem and leaves in response to the water potential gradient and osmotic potential gradient between the leaves and the soil. On the other hand, daytime radiation energy, which is balanced by the latent heat of the soil and plant, evaporates the water and thus increases the evapotranspiration of the soil-plant system. The evapotranspiration volume is estimated by the Penman-Monteith equation, which is known as potential evapotranspiration $E T_{\mathrm{O}}$ (Monteith 1965). Crop evapotranspiration $E T_{\mathrm{C}}$ is estimated using a simplified soil-water balance model (Yuan et al. 2001) based on water uptake $Q$ and change of soil moisture storage. Change of soil moisture storage is determined from the mass change of the soil-plant system (Blizzard and Boyer 1980). In a steady state, crop evapotranspiration is equal to the water uptake. In the schematic, soil moisture content $\theta$ is changed by manipulating the water supply depth $\Delta h$ in the reservoir. The change of the soil moisture content affects crop evapotranspiration and water uptake. Thus, a steady state can be achieved at an optimum soil moisture content that depends on suitable water supply depth. Based on the soil water balance model, daily data from the change of soil moisture storage is used to determine the soil-plant water status. The crop evapotranspiration and potential evapotranspiration by the Penman-Monteith equation are used to determine the crop coefficient (Allen et al. 1998).

\section{Experimental setup}

Figure 2 shows the experimental setup. A modified subsurface irrigation system was built for a plant pot containing commercial organic soil (9) (Masaki, RF-7, Nagasaki-shi, Nagasaki, Japan). The soil composition was $18.8 \%$ sand, $12.5 \%$ silt, $12.5 \%$ clay and $56.2 \%$ organic compost. The soil was placed in the pot in increments of $10 \mathrm{~cm}$, and each addition was manually compressed with a steel plate, giving a packed dry bulk density of $0.18 \mathrm{~g} / \mathrm{cm}^{3}$. The soil moisture content at the packed bulk density was $0.42 \mathrm{~m}^{3} / \mathrm{m}^{3}$. The soil

Fig. 1 Schematic of the system for modified subsurface irrigation

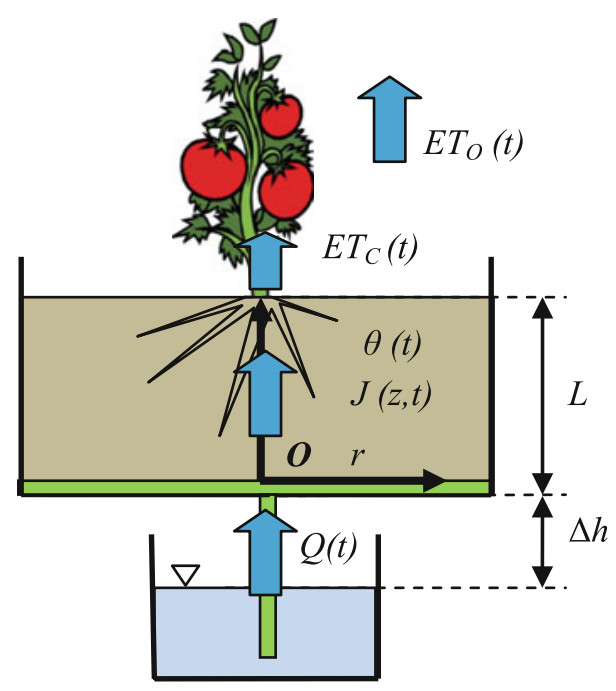




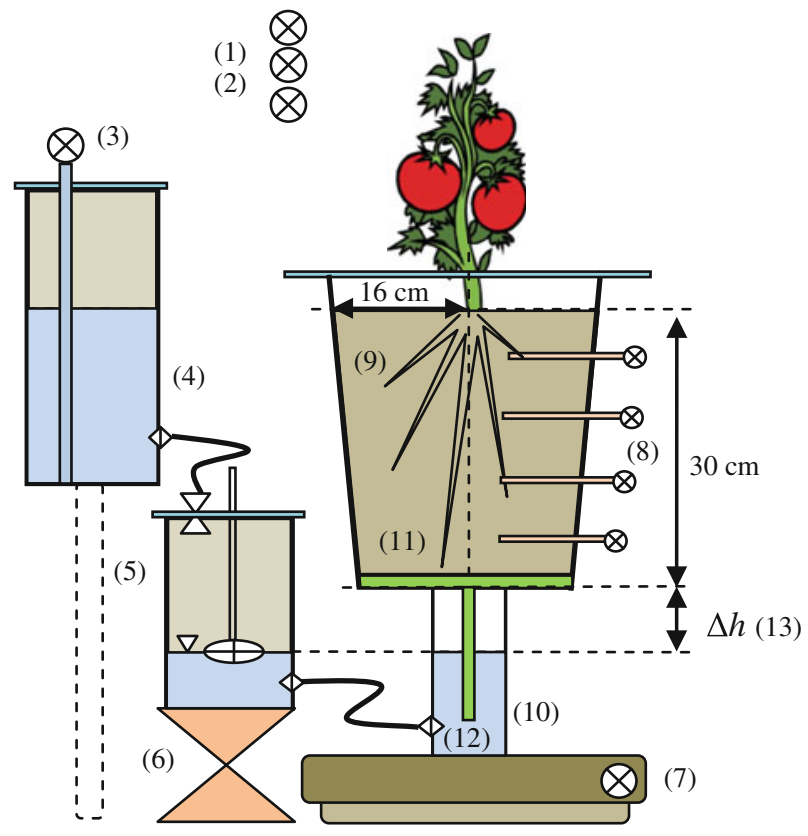

Fig. 2 Experimental setup for the modified subsurface irrigation system

Table 1 Fibrous interface characteristics in the experiment

\begin{tabular}{lllllll}
\hline Interface type & $\begin{array}{l}\text { Absorption } \\
\text { rate }(\mathrm{cm} / \mathrm{min})\end{array}$ & $\begin{array}{l}\text { Absorption } \\
\text { quantity } \\
(\%)\end{array}$ & $\begin{array}{l}\text { Porosity } \\
(\%)\end{array}$ & $\begin{array}{l}\text { Thickness } \\
(\mathrm{mm})\end{array}$ & Size $(\mathrm{cm})$ & $\begin{array}{l}\text { Weight } \\
\left(\mathrm{g} / \mathrm{m}^{2}\right)\end{array}$ \\
\hline $\begin{array}{l}\text { Horizontal interface } \\
\text { (Toyobo 7210s, } \\
\text { Kita-ku, Osaka, Japan) }\end{array}$ & $\begin{array}{c}5.5 \\
\text { (horizontal) }\end{array}$ & 750 & 90 & 2.0 & 22.0 & 210 \\
$\begin{array}{l}\text { Vertical interface } \\
\text { (Toyobo A-1, Kita-ku, } \\
\text { Osaka, Japan) }\end{array}$ & 2.0 (vertical) & 160 & 80 & 0.8 & $2 \times 15^{\mathrm{a}}$ & 270 \\
\hline
\end{tabular}

a Width and height of the interface in the vertical position and in two layers

surface was covered with a heat insulator so that the effect of thermal conduction by the soil was assumed to be zero. A small reservoir (10) is positioned under the pot and water rises up to a fibrous interface (11) through a fibrous string (12). The fibrous material characteristics are shown in Table 1. Infiltration of water to the soil above the fibrous interface is achieved by capillary rise. The soil moisture content was determined by setting a suitable water supply depth $\Delta h(13)$ using a manual jack (6) below a level regulator water tank (5). Two test pots, each with a fibrous interface of $22 \mathrm{~cm}$ in diameter were used. The pot with a plant is denoted as Pot A and the pot without a plant as Pot B.

The water used by the soil and the plant was determined from the change in water level in the water supply tank (4), measured with a magnetostrictive-type water level sensor (3) (Watty, HL-G1-0200-R-S, Shinagawa-ku, Tokyo, Japan). Hereafter, this is denoted as "water consumption." The microclimate parameters inside the phytotron were measured 
using an air temperature-humidity sensor (2) (Vaisala, HMP155, Vantaa, Helsinki, Finland) and a solar radiation sensor (1) (Li-Cor, LI-190, Lincoln, NE, USA). A set of capacitance-type soil moisture sensors (8) (Decagon, EC-5, Pullman, WA, USA) calibrated for the organic soil were vertically positioned in order at four different soil heights at $5-\mathrm{cm}$ intervals above the fibrous interface. An electronic balance (7) (A\&D, GP32KS, Toshima$\mathrm{ku}$, Tokyo, Japan) was used to measure the change in soil and plant mass. The evapotranspiration rate was determined from the mass change and water consumption data. Hereafter, this is denoted as "crop evapotranspiration." A data logger (Graphtec, GL820, Totsuka-ku, Yokohama, Japan) was used to store the data from the sensors, and the sampling time was 5 min.

The experiment was conducted in a phytotron with dimensions of $1.8 \mathrm{~m}$ in height, $1.75 \mathrm{~m}$ in width and $1.75 \mathrm{~m}$ in length. The roof and walls of the phytotron are glass to allow entry of direct sunlight, except for the back wall, which is a metal sheet. The air temperature in the phytotron was set at $25^{\circ} \mathrm{C}$ from 06:00 to $18: 00$ and $15{ }^{\circ} \mathrm{C}$ from 18:00 to 06:00. The air humidity was set at $70 \%$ and the air flow from the floor was continuous at $0.5 \mathrm{~m} / \mathrm{s}$. The phytotron is located at the Faculty of Agriculture, Tokyo University of Agriculture and Technology in Fuchu, Tokyo. The experiment was conducted from July to September 2011 and tomato was used as the test plant. The tomato plant was prepared by a commercial germinator (Sakata Seed, YB-38, Tsuzuki-ku, Kanagawa, Japan) and was transplanted to the pot at the age of 30 days. Nutrients were supplied by adding liquid fertilizer of 5-5-5 (Hyponex, Yodogawa-ku, Osaka, Japan) to the water supply tank at a ratio of $1: 1000$.

The experimental schedule is shown in Table 2. The experiment was conducted as denoted by the number of days after transplanting. During the early growth period, from Day 1 to Day 30, $\Delta h$ was set at $0 \mathrm{~cm}$ to provide the maximum water consumption for the plant. From Day 31 to $55, \Delta h=-11 \mathrm{~cm}$ and from Day 56 to $90, \Delta h=-3 \mathrm{~cm}$ for each subsurface irrigation experiment. The change in water supply depth was made at Day 56 when the plant showed symptoms of water-stress. The measurements were analyzed based on selected Days at 45, 55, 65 and 75. The experiment was limited to the investigation of water flow and soil moisture distribution in the soil-plant system using the modified subsurface irrigation system.

\section{Results and discussion}

Effect of water supply depth on soil moisture content

Figure 3 shows the soil moisture content at different soil heights for Pot A and Pot B at Days 45, 55, 65 and 75 after transplanting. The results show that the volumetric water content (VWC) for the soil in Pot A decreased from Day 45 to Day 55. This is due to the increase in root water uptake in response to higher plant growth, thus resulting in lower soil

Table 2 Days after transplanting and corresponding water supply depth

\begin{tabular}{ll}
\hline $\begin{array}{l}\text { Days after } \\
\text { transplanting }\end{array}$ & $\begin{array}{l}\text { Corresponding water } \\
\text { supply depth, } \Delta h(\mathrm{~cm})\end{array}$ \\
\hline $1-30$ & 0 \\
$31-55$ & -11 \\
$56-90$ & -3 \\
\hline
\end{tabular}



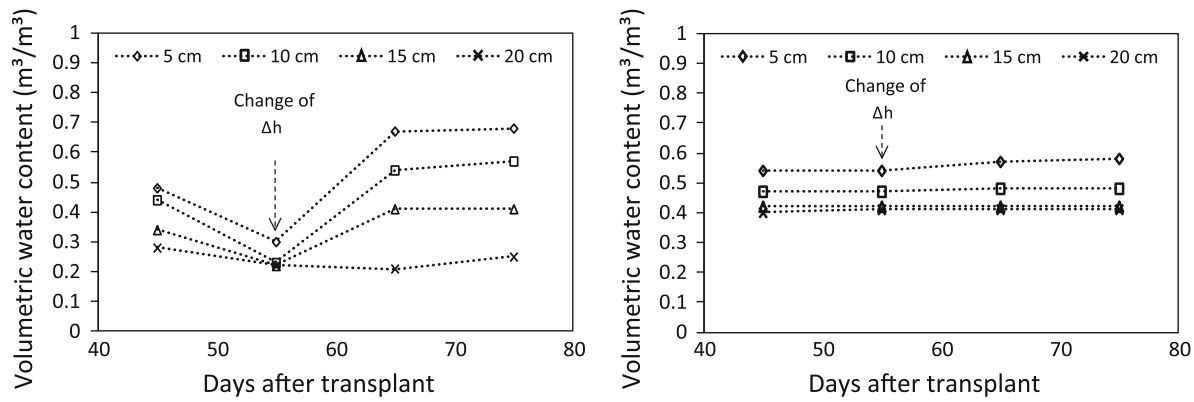

Fig. 3 Soil moisture content for Pot A (left) and Pot B (right) at Days 45, 55, 65 and 75 after transplanting

moisture content. The highest root water uptake was at a soil height of $5 \mathrm{~cm}$ observed from the lowest decrease in VWC. The soil moisture increased rapidly after water supply depth $\Delta h$ was changed from -11 to $-3 \mathrm{~cm}$. The highest increase was observed at a soil height of $5 \mathrm{~cm}$ at Day 65. A slight increase in VWC was observed from Day 65 to Day 75. For Pot $\mathrm{B}$, no substantial change in VWC was observed from Day 45 to Day 55. The soil moisture increased slightly after $\Delta h$ was changed from -11 to $-3 \mathrm{~cm}$ from Day 55 to Day 75 . However, the moisture increase in Pot B was not as high as in Pot A, which has a plant, although the change in $\Delta h$ was similar.

The phenomenon of water movement and distribution in unsaturated soil is related to the Buckingham-Darcy flux law for vertical flow as expressed by Eq. (1):

$$
J_{\mathrm{w}}=-K(h)\left(\frac{\delta h}{\delta z}+1\right)
$$

where $J_{\mathrm{w}}$ is water flux, $K(h)$ is unsaturated soil hydraulic conductivity, and $\delta h / \delta z$ is the gradient of matrix potential in the z-plane of the soil. The changes in soil moisture content and matrix potential at different soil depths in relation to the evaporation rate in the experiment can be determined by the integral form of the Buckingham-Darcy equation (Jury and Horton 2004). Moreover, it is important to understand the unique distribution of soil moisture caused by root growth in the soil observed from the results on Day 65 and 75 between Pot A and Pot B at the same water supply depth $\Delta h$ (Fig. 4). This can be explained by the water flow in the soil between Pot A and Pot B. For Pot A, the driving force of water flow in the plant was transpiration from the leaves, which generates root uptake. Thus the driving force of water flow in the soil was evaporation from the surface and the root

Fig. 4 Difference in soil moisture content in Pot A and Pot B at Day 65

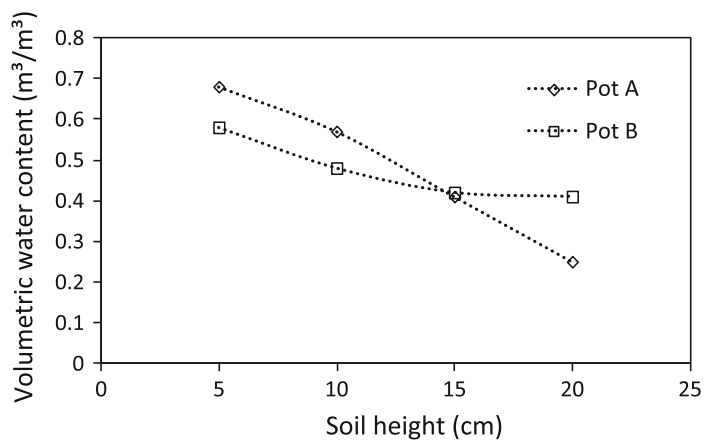


Fig. 5 Apparent soil water retention curve for the organic soil

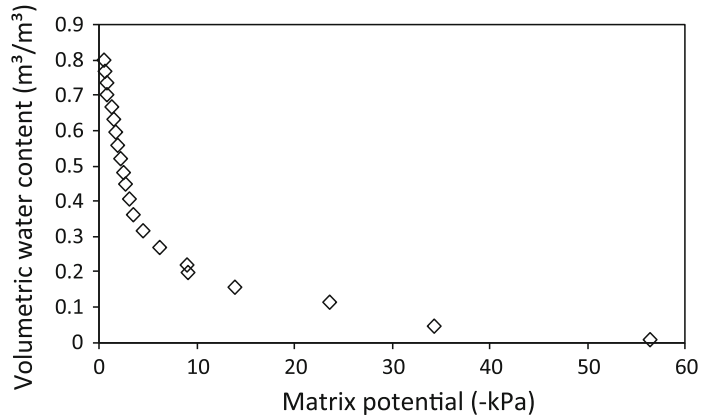

uptake. The water flow may be higher in Pot A due to the evaporation and root uptake than in Pot B, without a plant. The higher water flow may increase the potential gradient as a result of Darcy's Law as shown by the higher soil moisture in Pot A than that in Pot B (Fig. 4). The relationship between soil water potential and soil moisture is described by the soil water retention curve (Fig. 5). However, this characteristic from the experiment has not been analyzed in detail.

Potential evapotranspiration and water consumption

The potential evapotranspiration was calculated by using a modified version of the Penman-Monteith equation (Eq. (2)) by the Food and Agriculture Organization (FAO) of the United Nations. Potential evapotranspiration was determined based on a well-watered grass reference crop at a height of $0.12 \mathrm{~m}$, a fixed surface resistance of $70 \mathrm{~s} / \mathrm{m}$ and albedo of 0.23 (Allen et al. 1998):

$$
E T_{\mathrm{O}}=\frac{0.408 \Delta(R n-G)+\gamma \frac{37}{T+273} u_{2}\left(e_{\mathrm{s}}-e_{\mathrm{a}}\right)}{\Delta+\gamma\left(1+0.34 u_{2}\right)}
$$

where $E T_{\mathrm{O}}$ is potential evapotranspiration $(\mathrm{mm} / \mathrm{h}), R n$ net radiation at the crop surface $(\mathrm{MJ} /$ $\left.\mathrm{m}^{2} \mathrm{~h}\right), G$ soil heat flux density $\left(\mathrm{MJ} / \mathrm{m}^{2} \mathrm{~h}\right), T$ mean air temperature at a height of $2 \mathrm{~m}\left({ }^{\circ} \mathrm{C}\right), u_{2}$ wind speed at a height of $2 \mathrm{~m}(\mathrm{~m} / \mathrm{s}), e_{\mathrm{s}}$ saturated vapor pressure $(\mathrm{kPa}), e_{\mathrm{a}}$ actual vapor pressure $(\mathrm{kPa}), e_{\mathrm{s}}-e_{\mathrm{a}}$ saturated vapor pressure deficit $(\mathrm{kPa}), \Delta$ slope of vapor pressure curve $\left(\mathrm{kPa} /{ }^{\circ} \mathrm{C}\right)$ and $\gamma$ psychrometric constant $\left(\mathrm{kPa} /{ }^{\circ} \mathrm{C}\right)$.

Figure 6 shows the potential evapotranspiration $E T_{\mathrm{O}}$ and water consumption $Q$ of Pot A at Days 45, 55 and 65. The results show similar responses of $E T_{O}$ between each day,
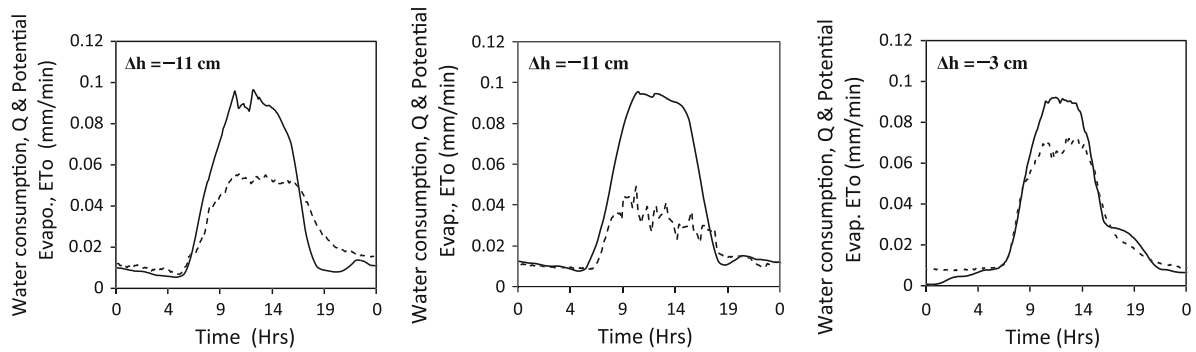

Fig. 6 Potential evapotranspiration (continuos line) and water consumption (dashed line) for Pot A at Days 45 (left), 55 (middle) and 65 (right) 
indicating similar climatic conditions during the 3 days. At Day $45, Q=0.05 \mathrm{~mm} / \mathrm{min}$ and was higher than that at Day 55 at $Q=0.03 \mathrm{~mm} / \mathrm{min}$. At Day $65, Q=0.07 \mathrm{~mm} / \mathrm{min}$, which was the highest. The variation in $Q$ between each day shows the effect of plant growth (from Day 45 to 55) and water supply depth $\Delta h$ change (from Day 55 to 65 ), which also corresponds to the soil moisture content (Fig. 3).

The relationship between the soil moisture content and the matrix potential is described by the soil water retention curve (Fig. 5). Thus, the potential gradient that drives the water flow in the soil-plant system can be related to the soil moisture condition. The transpiration establishes a potential gradient between the leaves and soil, thus creating the water flow. At $\Delta h=-11 \mathrm{~cm}$, the water flow from the reservoir was less than the root water uptake, thus decreasing the soil moisture content and reducing the water consumption. At $\Delta h=-3 \mathrm{~cm}$, the water flow increased and the soil moisture content recovered. The recovery is shown by the increase in water consumption from Day 55 to 65 (Fig. 6). For Pot B, the water consumption and soil evaporation rate were very small $(<0.4 \mathrm{~mm} /$ day $)$ at Days $45,55,65$ and 75 ; thus their results were disregarded.

The time lag shown by the difference in the response time of the water consumption from the potential evapotranspiration may indicate the water storage measured by the moisture capacitance of the soil-plant system (Hunt and Nobel 1987). The time lag observed from Day 45 and 55 was larger than that at Day 65, indicating that the capacitance was lower in the first 2 days. At Day 65, the immediate flow for water consumption with a small time lag indicates high moisture capacitance. The time lag shows that the water flow through the soil-plant system may have deviated from the steady state as a result of storage and release of moisture in the soil becomes significant (Nobel and Jordan 1983; Hunt and Nobel 1987). Many studies have considered the capacitance in their model (Williams et al. 1996, 2001; Hee and Ung 2007; Larcher and Wieser 1997), which enabled the determination of the time constant in the soil-plant system (Philips et al. 1997).

\section{Water consumption and crop evapotranspiration}

Figure 7 shows the water consumption $Q$ and crop evapotranspiration $E T_{\mathrm{C}}$ of Pot A, for Days 55 and 65. A similar response between water consumption and crop evapotranspiration was observed at Day 65. However, at Day 55 water consumption was lower than the crop evapotranspiration. The results can be related to a soil-water balance model that describes the relationship between the water consumption and crop evapotranspiration to
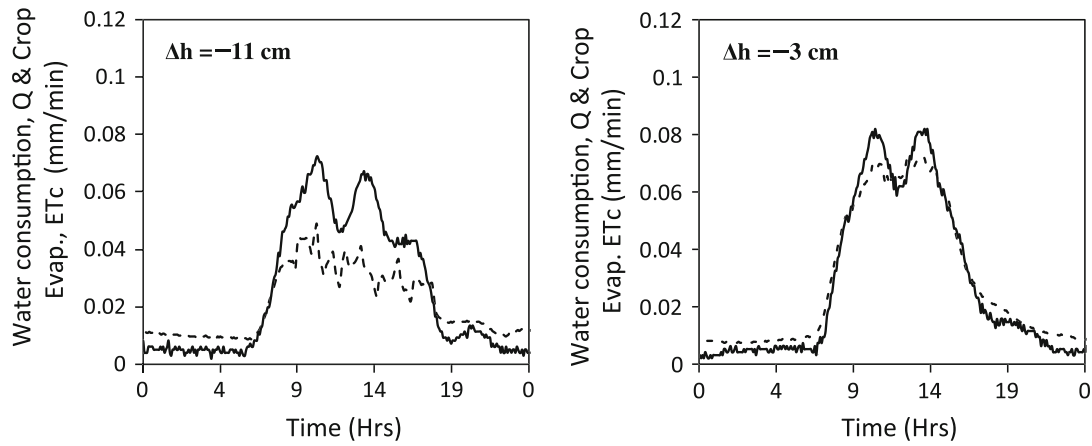

Fig. 7 Water consumption (dashed line) and crop evapotranspiration (continuos line) for Pot A at Days 55 (left) and 65 (right) 
the change of soil moisture storage. The model was used to analyze the water flow characteristic in the soil-plant system (Blizzard and Boyer 1980; Liu et al. 1998; Coelho et al. 2003).

The general equation describing the water balance in the soil is expressed by Eq. (3):

$$
\Delta \theta=J_{\mathrm{wi}}-J_{\mathrm{wd}}-E T_{\mathrm{C}}
$$

where $\Delta \theta$ is change of soil moisture storage, $J_{\text {wi }}$ precipitation and irrigation, $J_{\mathrm{wd}}$ drainage and deep percolation and $E T_{\mathrm{C}}$ evapotranspiration. The crop-water requirement is the amount of water required to compensate for the transpiration loss from the crop. Thus, for the modified subsurface irrigation system, the total crop water requirement and soil evaporation is the irrigation water requirement, which is the water consumption. From the experimental setup, the water balance model has been simplified (Yuan et al. 2001; Moiwo et al. 2011) and analysis of the results (Fig. 7) was made based on Eq. (4) with the assumption that drainage and deep percolation are equal to zero.

$$
\Delta \theta=\Sigma Q-\Sigma E T_{\mathrm{C}}
$$

The cumulative water consumption $\Sigma Q$ is the total moisture transferred to the soil-plant system (input) by water uptake and the cumulative crop evapotranspiration $\Sigma E T_{\mathrm{C}}$ is the total moisture removed from the soil-plant system (output). The water status of the soilplant system was determined based on the change of soil moisture storage $\Delta \theta$.

Table 3 summarizes the results for Day 55 and 65 with different water supply depth $\Delta h$ for a $24-\mathrm{h}$ period. At Day 55 when $\Delta h=-11 \mathrm{~cm}$, the change of soil moisture storage $\Delta \theta$ for Pot A was $-25.30 \%$, indicating that the rate of water loss through evapotranspiration was higher than the rate of water consumption. At Day 65, when $\Delta h=-3 \mathrm{~cm}, \Delta \theta$ was $+5.24 \%$, indicating that the rate of water loss was lower than the rate of water consumption. The change of soil moisture storage $\Delta \theta$ data can be related to the soil moisture content (Fig. 3). The decrease in $\Delta \theta$ to $-25.30 \%$ lowered the moisture content to an average of $0.28 \mathrm{~m}^{3} / \mathrm{m}^{3}$ while the increase in $\Delta \theta$ to $+5.24 \%$ raised the moisture content to an average of $0.48 \mathrm{~m}^{3} / \mathrm{m}^{3}$. At $\Delta h=-11 \mathrm{~cm}$, the soil moisture content was low because the water flow from the reservoir to the soil through the fibrous medium was restricted. The crop-water requirement was limited and water consumption was unable to compensate for the evapotranspiration loss. At $\Delta h=-3 \mathrm{~cm}$, the soil moisture content was high because water flow from the reservoir to the soil was permitted. The crop-water requirement was fully supplied and water consumption was able to compensate for the evapotranspiration loss.

Figure 8 shows the relationship between water consumption $Q$ and crop evapotranspiration $E T_{\mathrm{C}}$. The regression line shows that water consumption has a linear relationship with crop evapotranspiration. The gradient indicates the average level of soil-plant water

Table 3 Summary of water balance analysis for Pot A for the 2 days

\begin{tabular}{lll}
\hline Parameter & $\Delta h=-11 \mathrm{~cm}$ (Day 55) & $\Delta h=-3 \mathrm{~cm}$ (Day 65) \\
\hline$\Sigma Q(\mathrm{~mm})$ & 5.98 & 8.40 \\
$\Sigma E T_{\mathrm{C}}(\mathrm{mm})$ & 7.42 & 7.96 \\
$\Delta \theta(\mathrm{mm})(\%)$ & -25.30 & +5.24 \\
Soil-plant water status & Drying & Wetting \\
\hline
\end{tabular}



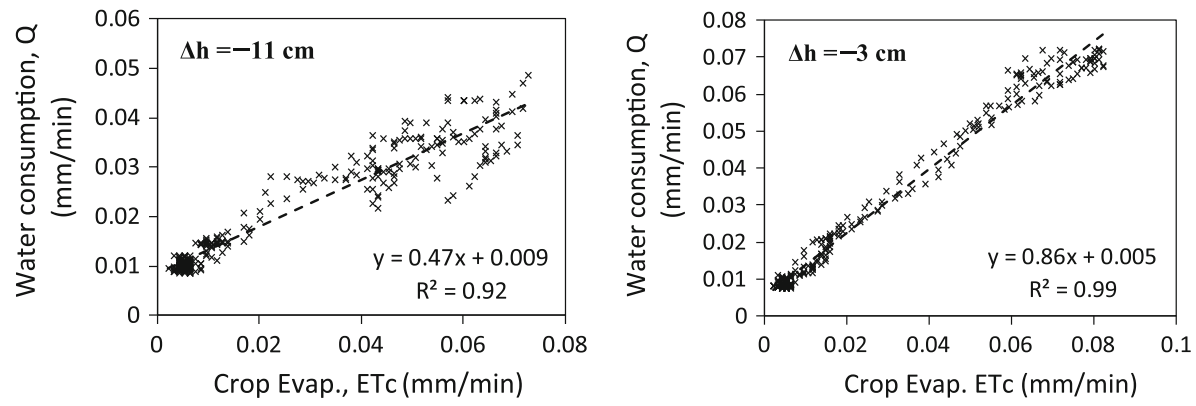

Fig. 8 Relationship between water consumption and crop evapotranspiration for Pot A at Days 55 (left) and 65 (right)

status either in the wetting state in which the rate of irrigation is higher than the rate of evapotranspiration or the drying state in which the rate of irrigation is lower than the rate of evapotranspiration. Based on this relationship, the measurement of water consumption can be used to determine crop evapotranspiration and to estimate crop-water requirement.

\section{Potential evapotranspiration and crop evapotranspiration}

Figure 9 shows the potential evapotranspiration $E T_{\mathrm{O}}$ and crop evapotranspiration $E T_{C}$ of Pot A at Days 55 and 65. The results indicate lower crop evapotranspiration at Day 55 than that at Day 65. This shows the effect of the atmospheric demand on the crop where the potential gradient is mainly between the atmosphere and the leaves. However, the water flow from soil to atmosphere was restricted by low soil hydraulic conductivity when $\Delta h=-11 \mathrm{~cm}$, thus significantly reducing crop evapotranspiration as shown at Day 55. At Day 65, the water flow increased when $\Delta h=-3 \mathrm{~cm}$, thus increasing the crop evapotranspiration.

The crop evapotranspiration at the 2 days indicates a temporal decrease at noon. The phenomenon can also be observed on water consumption as in Fig. 7. It was shown that when the crop evapotranspiration was enhanced during the maximum potential evapotranspiration, water supply was insufficient thus both crop evapotranspiration and water consumption dropped. The phenomenon may be due to the hydraulic conductivity of the
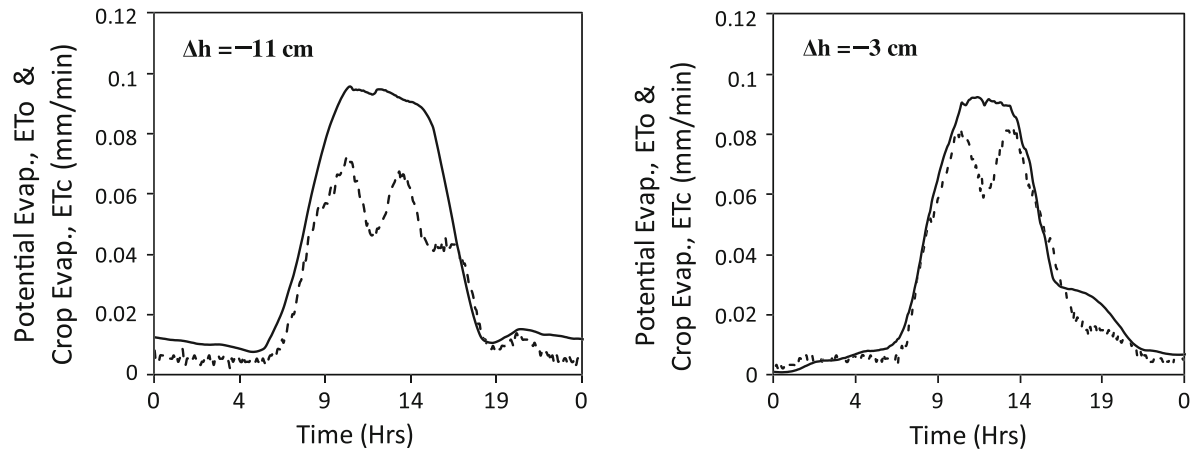

Fig. 9 Potential (continuos line) and crop (dashed line) evapotranspiration for Pot A at Days 55 (left) and 65 (right) 
Fig. 10 Relative evapotranspiration for Pot A at Days $45,55,65$ and 75

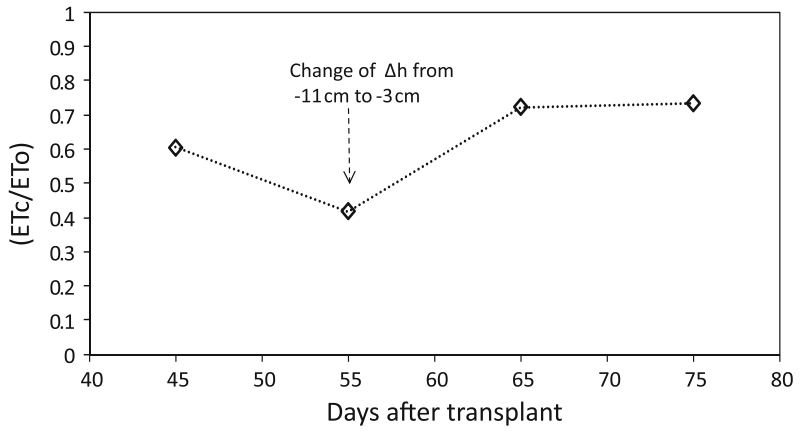

fibrous system. The water flow may be limited when the root uptake is increased thus causing temporal reduction of water consumption to the plant. However, the water flow characteristic by the hydraulic conductivity of the fibrous system has not been investigated in detail.

Figure 10 shows the relative evapotranspiration of Pot A at Days 45, 55, 65 and 75. It can be seen that the crop evaporation performance decreased from Day 45 to 55 and increased from Day 55 to 65 , when the water supply depth was changed from -11 to $-3 \mathrm{~cm}$.

Potential evapotranspiration calculated by Eq. (2) considered the plant and soil factors under the standard conditions of crop evapotranspiration $E T_{C}$ as

$$
E T_{\mathrm{C}}=K_{\mathrm{C}} E T_{\mathrm{O}}
$$

where $K_{\mathrm{C}}$ is a crop coefficient that depends on the plant characteristics, growth stage and soil moisture content. The standard condition refers to the evaporation demand from crops that are grown in a large field under optimum soil moisture, management and environmental conditions and achieve full production under the given climatic conditions (Allen et al. 1998). Crop coefficients are available for most plants (ASCE 1996) and generally vary with plant characteristics, growth stage and soil moisture content.

The results from Days 55 and 65 were used to determine the crop coefficient $K_{C}$ from the linear regression of potential evapotranspiration and crop evaporation based on Eq. (5) as shown in Fig. 11. The regression coefficient in the figure indicates that the crop coefficient differed for each day. The crop coefficient for Pot A at Day 55 was at 0.65 and at Day 65 at 0.85 . From the results, it was understood that the crop coefficient increased when the soil moisture content increased. The FAO determined the crop coefficient for tomato
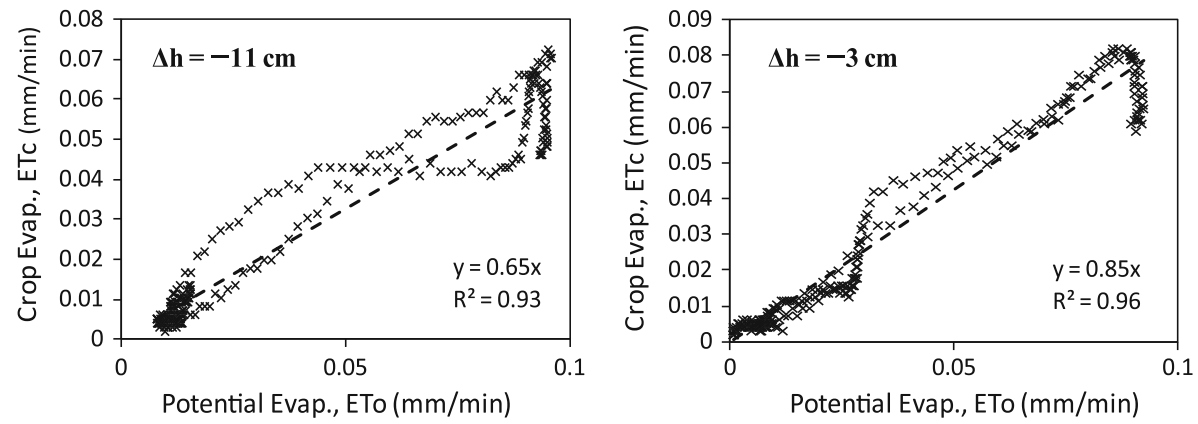

Fig. 11 Regression of potential and crop evapotranspiration at Days 55 (left) and 65 (right) 
Fig. 12 Root distribution above fibrous interface in Pot A

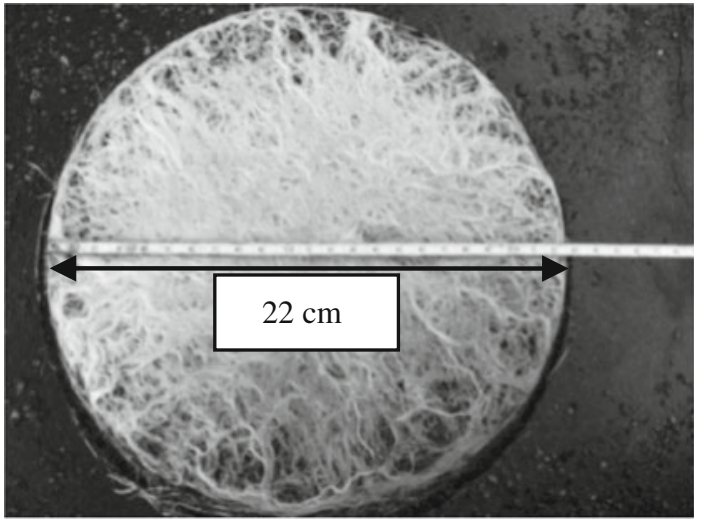

with a reference height of $0.6 \mathrm{~m}$ in three stages (ASCE 1996). The crop coefficients for the initial and middle stages are 0.61 and 1.15 , respectively. For the final stage, it ranges from 0.7 to 0.9 . The crop height for tomato is usually between 1.5 and $2 \mathrm{~m}$ and the crop coefficient may increase to 1.2 in the middle stage. The calculated crop coefficients in this experiment at 0.65 and 0.85 for a crop height of 1.6-1.7 $\mathrm{m}$ were within the reference crop coefficients by the FAO.

\section{Root distribution}

Figure 12 shows the root distribution of the plant in Pot A above the fibrous interface medium. The root distribution was uniform and covered almost the entire area of the interface. These findings suggest that root water uptake was very active in this area, which had the highest soil moisture content (Gregory 2006) near the interface and the water uptake may have been directly from the fibrous interface medium. This may be the reason for the immediate increase in water consumption during high evapotranspiration with minimum effect of soil moisture capacitance in the soil-plant system.

\section{Conclusions}

The crop-based irrigation system that combines both a continuous water supply and a sensing system for the plant-water requirement evaluated in this study based on -11 and $-3 \mathrm{~cm}$ of water supply depths. The results showed that the soil moisture content, crop evapotranspiration and water consumption were affected by the change in water supply depth in the reservoir. Thus, the optimum irrigation supply for the plant can be achieved by selecting an appropriate water supply depth. The irrigation management required from the modified subsurface irrigation system was successfully demonstrated. This system can be used as a water-saving tool for subsurface irrigation, which has a built-in crop-based measuring system for crop-water requirement and undisturbed irrigation supply. The objective of this study, which was to propose a simple strategy for precision irrigation to meet the plant-water demand, was met. In the future, this study will focus on modeling the water movement and distribution in the soil-plant system based on the modified subsurface irrigation system. 
Open Access This article is distributed under the terms of the Creative Commons Attribution License which permits any use, distribution, and reproduction in any medium, provided the original author(s) and the source are credited.

\section{References}

Allen, R. G., Pereira, L. S., Raes, D., \& Smith, M. (1998). Crop evapotranspiration: Guidelines for computing crop requirements. Irrigation and Drainage Paper No. 56, FAO, Rome, Italy.

ASCE (1996). Evaporation and transpiration. Chapter 4, Hydrology Handbook, 2nd ed. Task committee on Hydrology Handbook of Management Group D of the America Society of Civil Engineers. ASCE Manual No. 28, New York: ASCE.

Ayars, J. E., Phene, C. J., Hutmacher, R. B., Davis, K. R., Schoneman, R. A., Vail, S. S., et al. (1999). Subsurface drip irrigation of row crops: A review of 15 years of research at the water management research laboratory. Annual Water Management, 42, 1-27.

Blizzard, W. E., \& Boyer, J. S. (1980). Comparative resistance of the soil and the plant water transport. Plant Physiology, 66, 809-814.

Bonachela, S., Gonzalez, A. M., \& Fernandez, M. D. (2006). Irrigation scheduling of plastic greenhouse vegetable crops based on historical weather data. Irrigation Science, 25, 53-62.

Camp, C. R. (1998). Subsurface drip irrigation: A review. Transactions of the ASAE, 41(5), 1353-1367.

Coelho, M. B., Villalobos, F. J., \& Mateos, L. (2003). Modeling root growth and the soil-plant-atmosphere continuum of cotton crops. Agricultural Water Management, 60, 99-118.

Giorio, P., \& Giorio, G. (2003). Sap flow of several olive trees estimated with the heat-pulse technique by continuous monitoring of single gauge. Environmental and Experimental Botany, 49, 9-21.

Gregory, P. J. (2006). Plant roots: Their growth activity and interaction with soils. Oxford: Blackwell.

Hee, L. Y., \& Ung, P. S. (2007). Evaluation of a modified soil-plant-atmosphere model for CO2 flux and latent heat flux in open canopies. Agricultural and Forest Meteorology, 143, 230-241.

Hunt, E. R., Jr, \& Nobel, P. S. (1987). Non-steady-state water flow for three desert perennials with different capacitances. Australian Journal of Plant Physiology, 14, 363-375.

James, G. J. (1988). Principles of farm irrigation system design (p. 543). New York: Wiley.

Jones, H. G. (2004). Irrigation scheduling: advantages and pitfalls of plant-based method. Journal of Experimental Botany, 55(407), 2427-2436.

Jones, H. G., \& Leinonen, I. (2003). Thermal imaging for the study of plant water relations. Journal of Agricultural Meteorology, 59, 205-214.

Jury, W. A., \& Horton, R. (2004). Soil physics (6th ed.). New York: Wiley.

Larcher, W., \& Wieser, J. (1997). Water relation of the whole plant. Physiological plant ecology: Ecophysiology and stress physiology of functional groups. Berlin: Springer.

Liu, Y., Teixeira, J. L., Zhang, H. J., \& Pereira, L. S. (1998). Model validation and crop coefficient for irrigation scheduling in the North China Plain. Agricultural Water Management, 36, 233-246.

Moiwo, J. P., Tao, F., \& Lu, W. (2011). Estimating soil moisture storage change using quasi-terrestrial water balance method. Agricultural Water Management, 102, 25-34.

Monteith, J. L. (1965). Evaporation and environment. In G. E. Fogg (Ed.), The state and movement of water in living organisms. Cambridge: University Press.

Nalliah, V., \& Ranjan, S. R. (2010). Evaluation of a capillary irrigation system for better yield and quality of hot pepper (Capsicum annum). Journal of Applied Engineering in Agriculture, 26(5), 807-816.

Nobel, P. S., \& Jordan, P. W. (1983). Transpiration streams of desert species: Resistances and capacitances for a $\mathrm{C}_{3}, \mathrm{a} \mathrm{C}_{4}$ and a CAM plant. Journal of Experimental Botany, 34(147), 1379-1391.

Philips, N., Nagchaudhuri, A., Oren, R., \& Katul, G. (1997). Time constant for water transport in loblolly pine trees estimated from time series of evaporative demand and stem sapflow. Trees, 11, 412-419.

Raine, S. R., Meyer, W. S., Rassam, D. W., Hutson, J. L., \& Cook, F. J. (2005). Soil-water and salt movement associated with precision irrigation system-research investment opportunities. Final Report to the National Program for Sustainable Irrigation. CRCIF report number 3.13/1. Cooperative Research Center for Irrigation Futures, Toowoomba.

Shibusawa, S. (1989). Speaking plant approaches in phytotechnology. Agriculture and Horticulture, 64(4), 475-482. (in Japanese).

Slatyer, R. O. (1967). Plant water relationships. New York: Academic Press.

Smith, R. J., \& Baillie, J. N. (2009). Defining precision irrigation: A new approach to irrigation management. Research Bulletin, National Program for Sustainable Irrigation, Land and Water Australia. http://www.irrigationfutures.org.au/publications.asp. Accessed 1 Feb 2012. 
Williams, M., Law, B. E., Anthoni, P. M., \& Unsworth, M. H. (2001). Use of a simulation model and ecosystem flux data to examine carbon-water interaction in Ponderosa Pine. Tree Physiology, 21, 287-298.

Williams, M., Rastetter, E. B., Fernandes, D. N., Goulden, M. L., Wofsy, S. C., Shaver, G. R., et al. (1996). Modeling the soil-plant-atmosphere continuum in a Quercus-Acer stand at Harvard Forest: the regulation of stomata conductance by light, nitrogen and soil/plant hydraulic properties. Plant Cell and Environment, 19, 911-927.

Yuan, B. Z., Kang, Y., \& Nishiyama, S. (2001). Drip irrigation scheduling for tomatoes in unheated greenhouses. Irrigation Science, 20, 149-154. 